
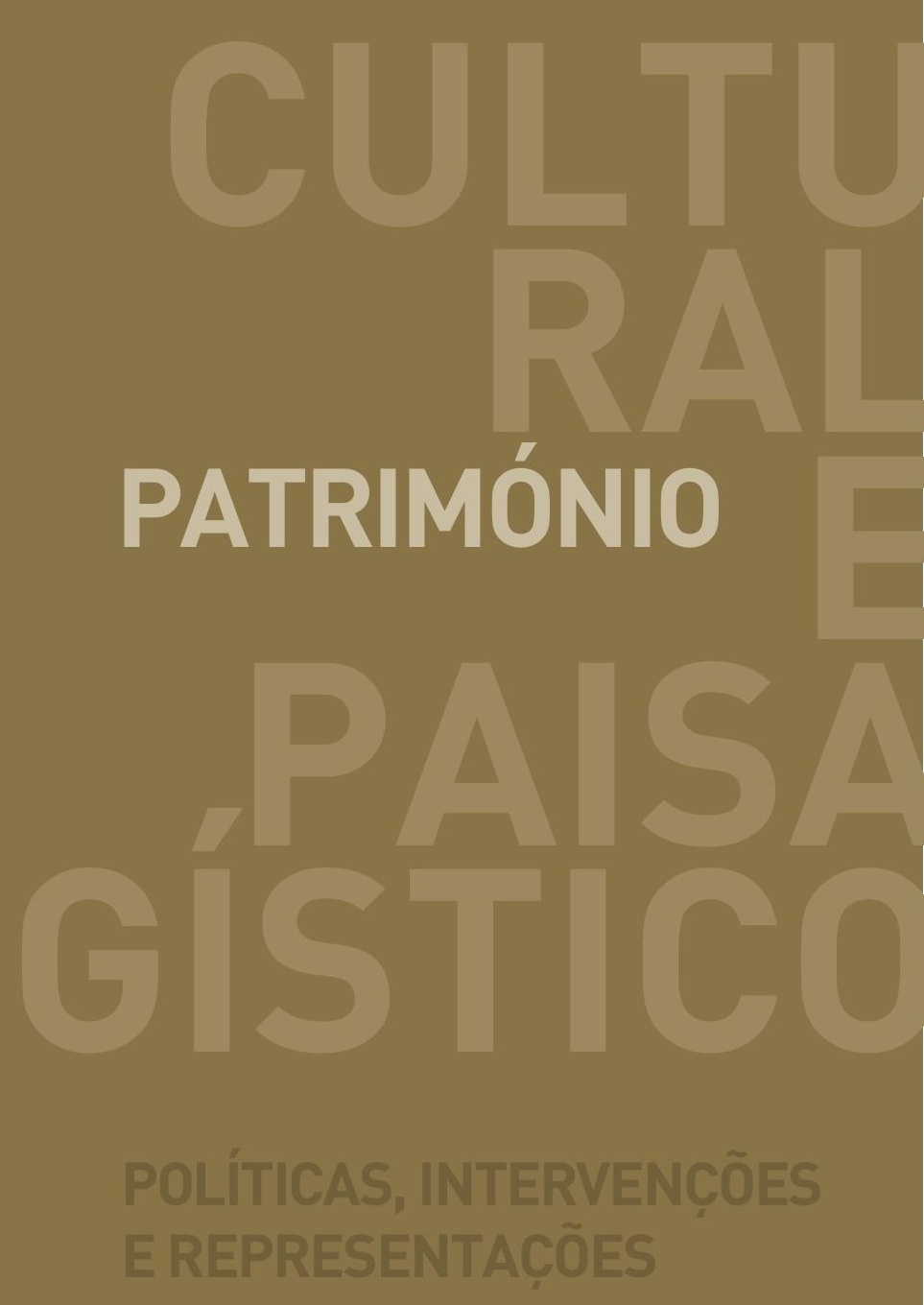

PAULO CARVALHO

JOÃO LUÍS J. FERNANDES 


\section{TERRITÓRIOS TURÍSTICOS, PAISAGENS E MEMÓRIAS \\ DO HOLOCAUSTO - CASO PARTICULAR DO CAMPO \\ PRISIONAL E DO GUETO DE THERESIENSTADT, NA ATUAL REPÚBlicA CHECA ${ }^{41}$}

\section{O turismo, as paisagens culturais e a evocação \\ do sofrimento e do macabro}

Pelas suas características de organização em rede, a atividade turística envolve um crescente número de atores e tem assumido uma gradual importância na (re) modelação da imagem dos lugares e na definição de planos de afirmação estratégica em múltiplas escalas geográficas, de pequenos territórios de matriz rural aos grandes centros urbanos. Neste jogo concorrencial, ganham protagonismo agentes que, num passado não muito longínquo, não se adivinhavam com a importância que agora possuem. Enquanto atores de um dos mais importantes canais de circulação e reprodução global de diferentes formas de capital, do financeiro ao humano, os turistas, os gestores e empresários turísticos são figuras relevantes num mundo agora mais imprevisível e sujeito a mudanças mais rápidas. Na atualidade, é difícil identificar e localizar com precisão os principais centros mundiais de poder económico e político. Esse núcleo de decisão será uma entidade difusa e móvel constituída ao mesmo tempo por unidades territoriais e por atores que se movimentam no espaço em estratégias multiterritoriais nem sempre fáceis de cartografar. Estes incluem também os decisores e planificadores

\footnotetext{
${ }^{41}$ Revisto e atualizado a partir do texto com o mesmo título publicado nas Atas do V Congreso Turismo y Desarrollo (Eumednet, Universidad de Malaga, 2011, 20 pp.)
} 
da atividade turística. A opção por investir mais neste lugar e menos naquele, de orientar os fluxos turísticos mais num sentido e menos noutro, de organizar projetos mais ou menos permeáveis aos contextos locais de implantação, assume destacada relevância na distribuição geográfica quer das mais-valias quer das externalidades desta atividade económica.

Porque se alargou a espaços geográficos longínquos e menos acessíveis, como o Sahara, a Amazónia, os Himalaias ou a Antártida; porque se expandiu apropriando o espaço na sua dupla geometria horizontal e vertical - são importantes as atividades turísticas de altitude, como o trekking de montanha e o alpinismo, mas também de profundidade, como a espeleologia e a caça submarina; porque tomou a paisagem na sua multidimensionalidade, valorizando-lhe a estética visual mas também as vertentes sonoras (soundscapes), olfativas (smellscapes) e gustativas (tastescapes); porque se democratizou e alargou a sua influência para as classes médias de um número crescente de países, com rápida difusão nos novos mercados dos países emergentes; mas também porque se diversificou e alargou para faixas demográficas que vão das crianças e dos adolescentes aos idosos, cada grupo agora considerado um alvo preferencial dos gestores e um potencial consumidor, o turismo é hoje uma atividade em rápida expansão geográfica, socioeconómica e cultural. Este alargamento implica novos desafios. Pela sua centralidade estratégica, o turismo coloca-se no centro do debate político.

Esta expansão tem-se associado à diversidade, vista no duplo sentido da oferta e da procura. Aumentou o número de turistas em circulação e estes apresentam agora perfis mais heterogéneos. Ultrapassado o monolitismo do turismo de massas dos célebres três S's (Sand, Sea and Sun), seguindo paradigmas diferentes como o Novo Turismo, o Turismo Cultural ou o Turismo Criativo, a procura é hoje mais fragmentada, as práticas turísticas menos alinhadas por fluxos uniformizados de massas e as paisagens do turismo mais diversificadas (Richards e Wilson, 2006).

É nesse sentido que tem aumentado a procura de paisagens pelo que estas evocam e simbolizam. Um lugar afirma-se pelos equipamentos que possui, pela estética, pela materialidade que se mostra quando ali se chega. Esta perspetiva é, contudo, estreita face ao que hoje se busca. O território é cada vez mais sentido e apropriado como espaço de vivências e narrativas. Mais que a morfologia da paisagem expressa pelas cores, pelas expressões visuais da natureza ou pelas matérias da ação humana, os lugares ganham importância porque se associam 
ao passado e à memória de acontecimentos e personagens. Os lugares ganham centralidade topobiográfica porque ali ocorreu algo, ali nasceu alguém relevante, ali passaram férias algumas celebridades, ali faleceu uma outra personagem. Também não é indiferente se, neste ou naquele lugar, foi rodado algum filme ou escrita uma obra literária, foram registadas estas ou aquelas fotografias, foi pintado um quadro famoso. É neste sentido que os lugares têm tirado partido de personagens como fotógrafos, escritores, pintores ou cineastas. É certo que o espaço poderá ter influenciado os traços de obras criativas mas é também importante analisar como, neste contexto pós-moderno de incessante procura de identidades de distinção, cada lugar territorializa as representações que antes terá inspirado. Por territorialização entenda-se o ato de se assumir uma obra criativa, patrimonializando os espaços que a terão suscitado. Aqui se incluem os que se associam à biografia pessoal (topobiografia) do autor ou, se for esse o caso, como na literatura e no cinema, à trajetória desta ou daquela personagem.

Vivem-se tempos contraditórios e paradoxais, facto que se reflete na procura turística, também esta contraditória, paradoxal e diversificada. Num contexto de maior insegurança e de multiplicação de medos, a sociedade reaproxima-se do passado e, num "frenesim patrimonial e comemorativo", sustenta uma vaga memorial de fundo (Lipovetsky e Charles, 2011: 89). Esta construção patrimonial da paisagem confere espessura ao espaço geográfico, regista acontecimentos, celebriza momentos históricos, comemora vidas de heróis reais ou fictícios e densifica lugares que, deste modo, se levantam da indiferença.

Estas memoryscapes e as respetivas estratégias de patrimonialização passam também pela relevância da ocorrência macabra, pela vida não do filantropo mas do anti-herói, do vilão que rouba, perturba a ordem social ou, no limite, assassina e deixa um rasto de sangue. Neste sentido, a paisagem é a materialização da memória de um contexto que deixou marcas negativas como um acidente, um regime repressivo, atos isolados ou sistemáticos de violação dos direitos humanos e de crueldade. Os acontecimentos passam mas a atmosfera da sua ocorrência continua a marcar paisagens.

Estas representações territoriais associadas à face sombria da vida humana individual ou coletiva podem apresentar um duplo sentido. Por um lado, expressam construções ideológicas e políticas, escolhas seletivas de acontecimentos 
e personagens que reforçam os poderes instituídos e sustentam metanarrativas abrangentes. Por outro, este reforço simbólico da paisagem vai ao encontro das novas procuras turísticas. Neste contexto de fluxos turísticos mais segmentados e de nicho, o Dark Tourism (Stone, 2006) sintetiza um conjunto diversificado de práticas e lugares associados a acontecimentos ofensivos da vida e da dignidade humana mas evoca também a memória de personalidades históricas consideradas relevantes, memória de quem continua vivo mas também dos que já desapareceram e deixaram no corpo sepultado um objeto de culto. Por isso os cemitérios são centrais nesta categoria turística.

São muitos os lugares que, no passado, estiveram associados ao drama e ao sofrimento. Todavia, para Gregory Ashworth (2004), nem todos são passíveis de patrimonialização e relevância turística. Para este autor, a afirmação deste património dependerá de múltiplos fatores: a maior ou menor identificação do turista com os protagonistas destes eventos, em especial as vítimas; a relação das atrocidades cometidas com sistemas político-ideológicos de domínio de um grupo sobre outro; a raridade ou a larga escala e dimensão relevante do acontecimento e, por último, a proximidade temporal ou a larga divulgação da ocorrência por veículos como a educação e as indústrias culturais, como sucede com o tráfico de escravos africanos entre os séculos XVI e XIX e, como se verá adiante, o Holocausto judaico durante a II Guerra Mundial, como também se comprova em Spargo e Ehrenreich (2010). Para Ashworth (op. cit:: 96), "The Holocaust of the Jewish people in Europe from 1933-45 as a culmination of a much longer persecution, and the pursuit of the Atlantic Slave Trade from the sixteenth to the nineteenth centuries, have both the necessary multimillionscale and multicentury longevity. Both are memorialized through many specific sites, occurrences and individuals and both have powerful contemporary implications for personal and group identities and for political nation and state building. Both are currently used in part for tourism although tourism was not, and remains not, the main motive for heritage interpretations in either case. Finally both were world scale, long term, systematic, top-down impositions of injustice and oppression from one large group of perpetrators upon another equally group of victims. Identification is thus so widespread in practice that it may be extended to include all bumanity in one way or another. We are thus all involved whether as tourists or not". 
Esta patrimonialização pode ocorrer in situ, isto é, no lugar efetivo do acontecimento ou, pelo contrário, ex situ, num espaço deslocalizado de representação, como um museu. Campos de batalha, prisões, lugares de acidentes, túmulos e cemitérios, espaços museológicos de diversa natureza ou memoriais, fazem parte desta geografia do macabro, da violência e/ou da celebração/comemoração. Para Philip R. Stone (op. cit.), a diversidade destes lugares pode sistematizar-se entre os espaços Light e os espaços Hard. Os primeiros encontram-se associados a uma exibição ligeira, descontextualizada e encenada do macabro para fins de entretenimento, como algumas narrativas do fantástico representadas em parques temáticos (Figuras 1 e 2). Os segundos englobam lugares de evocação direta e contextualizada de acontecimentos históricos comprovados. Se no primeiro caso teremos um turismo sombrio de entretenimento familiar em paisagens plastificadas, no segundo caminha-se para paisagens simbólicas de evocação pesada orientada por grupos étnicos e político-ideológicos específicos, como os campos de concentração da II Guerra Mundial no leste europeu ou os espaços do Apartheid na África do Sul (Ashworth, op. cit.).
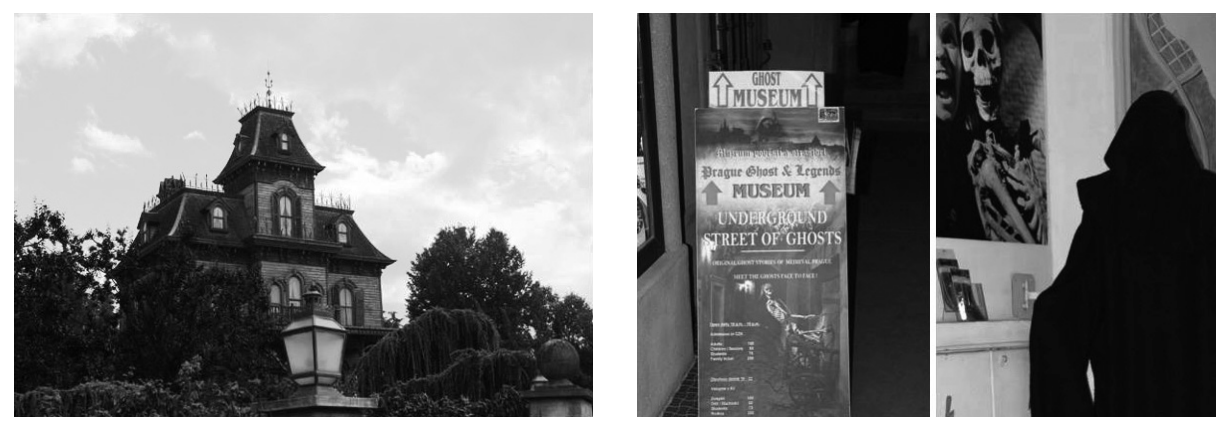

Figura 1 (esquerda) - Imagem exterior de uma casa assombrada, no parque temático Eurodisney (Paris). Figura 2 (direita) - Espaço museológico evocativo do macabro, do mundo subterrâneo e de figuras fantasmagóricas, em Praga (República Checa).

A procura destes territórios tem sido fomentada pela cobertura das indústrias culturais e criativas, em áreas como o cinema, a televisão e o jornalismo. O acompanhamento noticioso dos acontecimentos mais mediáticos (como as mortes de Diana de Gales, em 1997, e de Michael Jackson, em 2009), o documentário histórico ou o filme de evocação deste ou daquele contexto histórico, como 
a Inquisição e o Holocausto, a escravatura e a guerra, suscitam curiosidades e criam públicos. Contudo, a visita a lugares como, por exemplo, o castelo de Edimburgo ou a Torre de Londres, não sugere o mesmo sentimento em diferentes visitantes que não interpretam no local as mesmas narrativas nem valorizam os mesmos parâmetros de observação (Foley and Lennon, 2000). Aos que veem estes edifícios como meras peças de arquitetura militar, acrescentem-se os que leem os personagens e os acontecimentos que ali ocorreram; àqueles que interpretam estes monumentos como instrumentos de afirmação política, somem-se os que focam sobretudo a violência que ali terá ocorrido. Na verdade, à variedade de espaços que invocam narrativas dramáticas e de morte, corresponde a diversidade dos olhares e da procura. Para Ashworth (op. cit.: 95), "These encompass many motives (...) from a pilgrimage of penance and repentance for an assumed complicity (a 'mea culpa tourism'), through a quest for identity ('roots tourism'), a less personally engaged search for knowledge, understanding and enlightenment ('edutourism'), a social mission to shape more desirable or responsible future ('lest we forget' or 'never again tourism), to much darker and less socially acceptable emotions where gratification is obtained from violence and suffering, becoming in its extreme from a 'sadomasochistic pornographic tourism". Numa síntese possível, estes fluxos turísticos de nicho podem dividir-se em três grupos (figura 3).

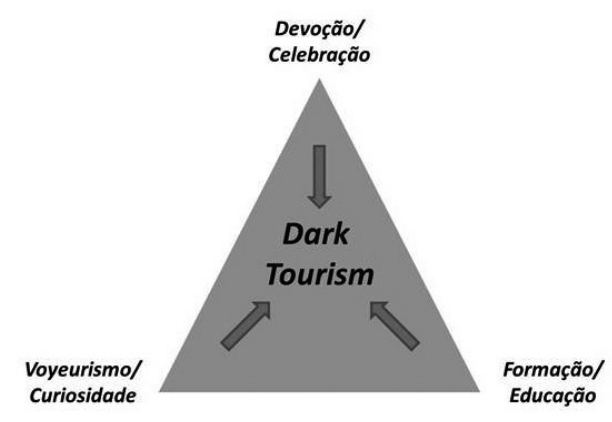

Figura 3 - Segmentação da procura no turismo alternativo do macabro e do drama (Dark Tourism).

Os lugares da dor e da violência são procurados por turistas que o fazem por devoção, celebração ou comemoração. Em muitos casos seguem filiações 
e correntes de devoção tribais. Assim se visita o túmulo de Jim Morrison, no cemitério Pére Lachaise, em Paris ou, ainda no mesmo local, os restos mortais de Edith Piaf. Este mesmo sentimento acompanha parte dos turistas que visitam a Mansão Graceland, antiga residência e local de sepultura de Elvis Presley, em Memphis. Como se verá mais adiante, incluem-se nesta categoria os grupos de turistas judeus que visitam lugares evocativos do Holocausto ocorrido durante a II Guerra Mundial. Nestes fluxos étnicos, promovem-se filiações de diáspora e evocam-se acontecimentos de relevância coletiva. Como refere Ashworth (op. cit.: 363), "Victims may use atrocity heritage for a deliberate fostering of group cobesion, place identification or ideological legitimation. The memorability of atrocity simply makes it a powerful instrument for those who identify themselves as victims".

A visita a lugares evocativos de acontecimentos dramáticos pode ainda ocorrer por curiosidade, por voyeurismo, pelo simples prazer de ali se ter estado, de ali se ter registado o momento numa fotografia. Neste grupo incluem-se ainda os turistas que ocupam tempos de lazer e entretenimento, em lugares considerados por Philip R. Stone (op. cit.) como a versão light do turismo do macabro. O percurso turístico por espaço associados à morte, ao sofrimento e à violência incluem-se também na ampla categoria do turismo cultural. Procuram-se espaços que evoquem acontecimentos e contextos histórico-geográficos. Visita-se o Coliseu de Roma e imaginam-se as lutas de gladiadores para se entender o Império Romano, como se visita a Ilha de Goreia, ao largo da costa do Senegal para se compreender a escravatura. Neste sentido, alguns lugares de drama e sofrimento podem ser espaços pedagógicos de formação para a cidadania e salvaguarda do futuro.

$\mathrm{Na}$ verdade, na apropriação turística destes lugares podem coexistir leituras individuais e coletivas, estas últimas seguindo filiações históricas, de nacionalidade, étnicas ou religiosas, que se alimentam de fatores patrimoniais de coesão. Estas leituras coletivas seguem também agregações de natureza pós ou hipermoderna, como as que unem os seguidores de um clube ou os admiradores de um filme, uma atriz ou um cantor. Por isso, estes serão lugares de reflexão, para uns, de emoção, para outros, de entretenimento, para outros ainda, facto que cria dificuldades de gestão e orientação estratégica dos mesmos e potencia riscos, como a apropriação lúdico-comercial e a excessiva mercantilização destes espaços. Este risco é tanto maior quanto menor é a identificação entre os visitantes, as 
vítimas e os agressores, questão importante sobretudo no denominado, ainda seguindo a terminologia de Stone (op. cit.), dark tourism hard. Esta questão pouco se coloca na vertente light desta tipologia turística, precisamente porque esta se organiza para um turista-consumidor, como ocorre no citado exemplo de alguns parques temáticos que mais não fazem que brincar com a morte e a violência encenadas.

\section{Turismo e patrimonialização da II Guerra Mundial no continente europeu}

A proximidade temporal da II Guerra Mundial e a sua associação ao passado de gerações ainda vivas; o constante debate deste momento histórico, considerado relevante para a compreensão do mundo contemporâneo, o que justifica a centralidade desta matéria nos programas escolares; a sua frequente representação no cinema, na literatura ou na televisão e a localização europeia de alguns dos acontecimentos mais marcantes deste conflito bélico, fazem da Europa um importante território de memória das ocorrências vividas entre 1939 e 1945. Esta tendência de patrimonialização tem-se cruzado, no que à Europa de Leste diz respeito, com a entrada de países, regiões e cidades no jogo dos mercados turísticos concorrenciais, sobretudo depois da queda do Muro de Berlim, em 1989. Desde então, estes antigos territórios da esfera de influência soviética têm buscado uma redefinição identitária e procurado fatores de relevância geográfica.

É também neste sentido que se deve entender a classificação de espaços que recordam o comunismo, desde museus icónicos a antigas prisões ou cidades criadas e planificadas pelas estruturas centrais. Esta rede de lugares tem-se associado a uma nova tipologia turística, o Communist Heritage Tourism (ou Red Tourism), que envolve múltiplas procuras, que vão da simples curiosidade ao interesse da análise política de um passado muito recente e que marcou grande parte do século XX e da Guerra Fria (Ivanov, 2009; Light, 2000a e 200b).

A patrimonialização dos lugares associados à II Guerra Mundial segue a mesma linha, com a diferença que, no leste europeu, estas memoryscapes podem ter 
antecedido a queda dos regimes comunistas. Mesmo no período pré-1989, celebrou-se a memória deste conflito não como cartaz turístico mas com o propósito de valorização do papel libertador do Exército Vermelho que, vindo da ex-URSS, travou o domínio nazi e desmantelou, naquela frente, o domínio da Alemanha de Hitler. Como ocorreu com Terezin, que a seguir se apresentará, estes lugares foram espaços de propaganda e pedagogia dos valores idílicos e utópicos do comunismo de inspiração soviética.

Noutro registo, em Budapeste, ao longo de 300 metros na margem esquerda do Danúbio, próximo do parlamento húngaro, um memorial constituído por um conjunto de 60 pares de sapatos modelados em ferro e bronze segundo estilo dos anos (19)40, relembra os judeus assassinados e depois lançadas ao rio durante o regime fascista da II Guerra Mundial (Figura 4).

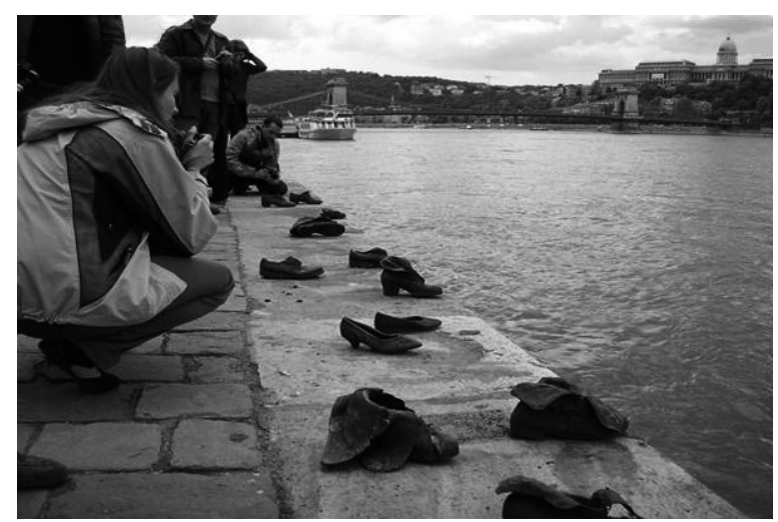

Figura 4 - O memorial Sapatos sobre a margem do Danúbio, em Budapeste, inaugurado em 2005 e criado por Gyula Pauer e Can Togay.

Esta evocação, hoje um dos pontos de interesse turístico na capital húngara, é um dos vértices da extensa rede de lugares que, por um lado, patrimonializam a II Guerra Mundial e, por outro, homenageiam as vítimas do Holocausto, em especial as de origem judaica. Desta rede fazem parte museus, memoriais de diversa natureza e paisagens simbólicas, como alguns cemitérios. Estes espaços de memória ocupam um lugar central neste turismo alternativo e nas políticas de identidade e afirmação política às quais estas celebrações se associam. Neste caso, não se trata de cemitérios que, como o Père Lachaise (em Paris), 
se podem denominar de personalidades, espaços simbólicos que ganham relevância pela identidade personalizada das celebridades que ali jazem. Tal como ocorre com o sepulcrário militar, em Colleville-sur-Mer (na Normandia, França), onde repousam os corpos de milhares de militares norte-americanos mortos em combate, neste tipo de cemitérios, que se poderão denominar de acontecimentos, mais que as personagens individuais, homenageia-se o grupo e o contexto histórico.

Também nesta linha se patrimonializam campos de batalha, como em Arnhem ou nas Ardennes, e lugares simbólicos como as praias da Normandia, espaços que se abrem ao denominado battlefield (ou war) tourism, mais uma categoria de nicho integrada no turismo de drama e sofrimento (Ryan, 2007).

Esta memorialização tem o seu epicentro num espaço urbano europeu. A cidade de Berlim, lugar central da II Guerra Mundial, do Holocausto e da Guerra Fria e ainda palco de um dos acontecimentos que marcou a Geografia Política europeia contemporânea (a queda do Muro, em 1989), tem-se reconvertido, requalificado e simbolicamente remodelado (Stangl, 2008). A recente aposta na arquitetura, na criatividade e num ambiente cosmopolita faz-se sob uma matriz urbana de acontecimentos e celebrações, na qual se inclui a memoryscape evocativa do nazismo, da II Guerra Mundial e do Holocausto. Na Berlim da pós-modernidade relembra-se a fragmentação da cidade e do continente europeu depois de 1945, patrimonializando-se elementos como fragmentos do Muro que separou este território urbano, algumas torres de vigia e uma das passagens, o célebre Checkpoint Charlie. Também em Berlim se localizam espaços de celebração de resistentes ao nazismo, como o memorial de Dietrich Bonhoeffer; se preservam paredes cravejadas de balas e estátuas danificadas durante os combates entre as tropas de Hitler e o Exército Vermelho; se identifica o lugar onde se erguia a chancelaria de Hitler, um complexo desenhado pelo arquiteto do Terceiro Reich Albert Speer e que incluía o refúgio onde o líder nazi terá sido morto; se identificam edifícios da Gestapo; se patrimonializa a Bebelplatz, onde, no dia 10 de maio de 1933, as SS e alguns grupos hitlerianos de juventude, inspirados pelos serviços de propaganda de Joseph Goebbels, queimaram cerca de 20 mil livros de, entre outros, escritores proscritos como Karl Marx, Thomas Mann, Erich Maria Remarque, Ernest Hemingway, Stefan Zweig e Jack London, judeus ou não, mas todos considerados uma ameaça à ideologia nacional-socialista. Esta cons- 
trução simbólica do espaço urbano passou também pela paradoxal destruição de lugares que correriam o risco de serem apropriados como santuários do movimento neonazi, como ocorreu com a prisão de Spandau, localizada em Berlim Ocidental e demolida em 1987 depois da morte do último prisioneiro, Rudolf Hess. Nesta cidade foram criados o Museu Judaico, de Daniel Libeskind, aberto ao público em 2001, e o Memorial do Holocausto, com arquitetura de Peter Eisenman, inaugurado em 2005, sessenta anos depois do fim da II Guerra Mundial. É assim que Berlim se torna um dos centros de atração de um turismo de filiação, memória e diáspora, sobretudo da população judaica. Esta cidade faz parte de uma rota de grupos que, vindos dos EUA e de outras regiões, celebram a sua identidade, homenageiam as vítimas e os antepassados e promovem a coesão interna da rede de judeus dispersos por diferentes países.

Este turismo de memória, filiação ou diáspora tem o seu hotspot nos campos de concentração do complexo Auschwitz-Birkenau (na Polónia) que, em 2009, recebeu cerca de 1 milhão e 300 mil visitantes ${ }^{42}$. Património Mundial desde 1979, estas traumascapes de alojamentos, câmaras de gás e crematórios simbolizam a violência e atraem turistas que ali se dirigem com diferentes motivações, distribuídos pelos três vértices referidos na Figura 3 (Tumarkin, 2005). Para Peter E. Tarlow, (2005: 48), "This spot symbolizes the pinnacle of European dark tourism. Here in this small Polish town, the victims are counted by millions. Now history reaches the surreal and mixes with it to become postmodern madness. Just as in Europe's battlegrounds or at its monuments, the past gives way to the present. The visitor may photograph grounds and buildings that have known the agony of death, but modern visitors see only life. (...) Some come to pay theirrespects, others come out of curiosity or because it is the thing to do. The agony of history becomes a tourism attraction once again".

Em muitos casos, os turistas associam a visita a Auschwitz-Birkenau com a passagem pelo distrito de Kazimierz, gueto de concentração e confinamento de população judaica em Cracóvia, durante a II Guerra Mundial. Há muito visitado por judeus dos EUA e de Israel, este destino ganhou especial importância depois

\footnotetext{
42 Valor publicado no site oficial destes antigos campos de concentração, em http://en.auschwitz. org.pl/ (consultado no dia 18 de junho de 2010).
} 
de representado no filme Schindler's List, realizado por Steven Spielberg em 1993 (Ashworth, 2002).

\section{O caso do Campo prisional de Theresienstadt (Terezín),} na atual República Checa ${ }^{43}$

$\mathrm{Na}$ atualidade com 3121 habitantes $^{44}$, a cidade de Terezín localiza-se numa superfície aluvial entre os rios Ohře (Eger) e Labe (Elba). Implantada num corredor estratégico entre Dresden e Praga, faz parte do Distrito de Litoměřice e localiza-se $60 \mathrm{~km}$ a norte da capital checa, nas proximidades da fronteira com a Alemanha (Figura 5).

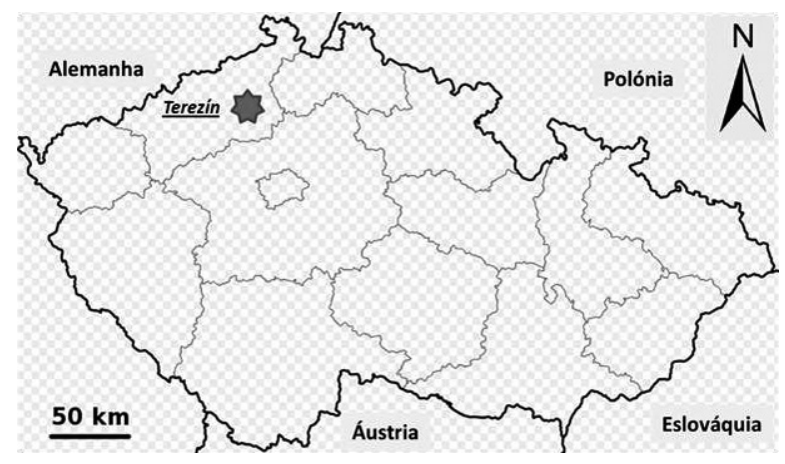

Figura 5 - Localização geográfica de Terezín, na República Checa e países envolventes.

Com origem numa obra militar do século XVIII, Terezín é composta por duas fortalezas, uma mais pequena e outra maior, a denominada fortaleza principal onde, no interior, foi crescendo a cidade. Construído durante o conflito entre

43 Os dados factuais e as estatísticas nesta análise de caso foram ou recolhidas no local ou retirados das obras Terezín Memorial (2009), Monument Terezín (2003) e Terezín Memorial (Vários anos).

${ }^{44}$ Dado recolhido em http://www.statnisprava.cz/, consultado a 19 de junho de 2011. 
o Império Austro-Húngaro e a Prússia, este é um lugar com passado associado à guerra como posto avançado para a defesa do vale do Elba, da Boémia e da capital Praga. Depois do fim do conflito com os prussianos, esta cidade planeada adquire alguma centralidade civil mas logo, na fortaleza mais pequena, se cria um presídio. Neste longo historial como cárcere, assinale-se o aprisionamento do estudante sérvio Gravilo Princip, autor do assassinato do Arquiduque Francisco Fernando, em Sarajevo, episódio que despoletou o início da Guerra Mundial de 1914-18, durante a qual também o pequeno forte de Terezín foi usado como prisão da monarquia dos Habsburgos (Figura 6).

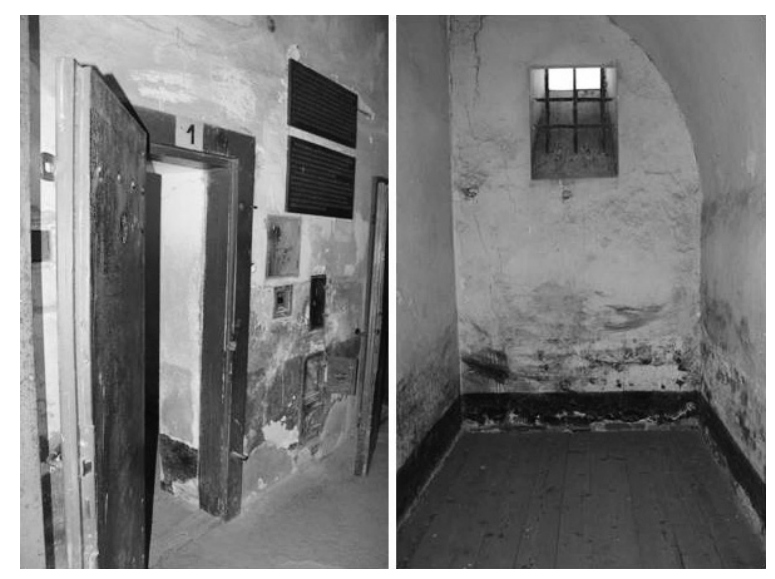

Figura 6 - Cela prisional de Gravilo Princip, associado ao assassinato do Arquiduque Franz Ferdinand ocorrido em 1914, na cidade de Sarajevo.

Em 1940, após o avanço de Hitler sobre a atual República Checa e a declaração do Protetorado alemão da Boémia-Morávia, a Gestapo instalou um campo prisional na pequena fortaleza de Terezín, depois da invasão renomeada com o topónimo germânico Theresienstadt. Este espaço prisional faz parte de um triângulo de lugares de repressão, constituído por outros dois vértices: o campo de concentração de Flossenbürg e um anexo deste, perto de Litoměřice. $\mathrm{Na}$ política de germanização dos territórios ocupados, as prisões, os campos de extermínio e toda a máquina de terror foram instrumentos fundamentais na estrutura ideológica do regime. 
Neste espaço de encarceramento em Terezín foram presos, torturados e executados judeus e outros grupos perseguidos pelo Terceiro Reich, como membros da resistência e de movimentos comunistas, estudantes subversivos e todos os que, de algum modo, se opuseram à Alemanha hitleriana. Para aqui foram enviados diplomatas, cientistas, escritores e músicos mas também cidadãos comuns; checos mas também polacos, alemães da oposição e, entre outros, vítimas dos antigos países da ex-União Soviética. Em 1944 estariam na pequena fortaleza cerca de 2000 presos. No fim da guerra, em 1945, esse valor ascendia a 5550. No total, pela prisão da pequena fortaleza terão passado 27000 homens e 5500 mulheres, facto que obrigou, entre 1940 e 1945, à sucessiva construção de novos alojamentos no interior do espaço abaluartado. Os surtos de doenças infeciosas como a desinteria e o tifo; uma dieta alimentar deficiente; trabalhos árduos estendidos por períodos de 10 a 14 horas, dentro e fora do forte - na manufatura de roupas, em minas, na construção de linhas de caminho de ferro ou de fossos defensivos; a tortura, a crueldade dos guardas e as execuções, fizeram da pequena fortaleza de Terezín um antro de elevada taxa de mortalidade.

Depois do conflito, este território de memória dos dramas e do sofrimento que acompanharam a II Guerra Mundial tornou-se um lugar de peregrinação. Ainda em 1945, os corpos das vítimas foram exumados e sepultados no Cemitério Nacional, na entrada da pequena fortaleza. Mais que o nome específico de cada pessoa enterrada, este espaço constitui o exemplo de um cemitério de acontecimento atrás referido, até porque uma parte dos corpos ali sepultados permanece com identidade desconhecida (Figura 7). Logo em 1947 foi criado o Memorial do Sofrimento Nacional, depois renomeado em 1964 como Memorial Terezín. Para a modelação desta memoryscape, têm colaborado especialistas, académicos e uma rede de instituições que representam as vítimas. Esta congregação de interesses foi importante quando, em 2002, parte significativa deste património foi destruído por uma inundação, risco ao qual Terezín é sensível dada a sua localização aluvial. O próprio governo da República Checa, que dá suporte financeiro ao Memorial, envolveu-se na recuperação dos estragos desta ocorrência, que afetou tanto a pequena como a fortaleza principal. 

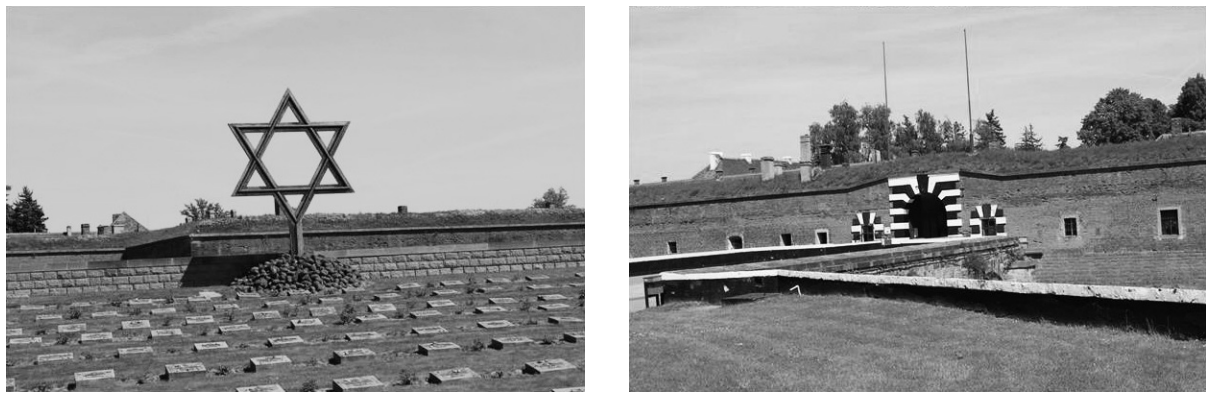

Figura 7 - Esquerda, a Estrela de David e o Cemitério Nacional.

Direita, a entrada na fortaleza pequena.

$\mathrm{Na}$ atualidade, este espaço mostra-se nas exposições museológicos que exibem objetos e filmes alusivos aos acontecimentos; nas celas de isolamento; nos cubículos que, com uma superfície limitada, enclausuravam grupos de prisioneiros excedendo em muito a lotação prevista; nos muros de fuzilamento e no recanto onde ocorreu um enforcamento; nos aposentos dos oficiais mas também nas salas de acolhimento e de interrogatório dos presos recém-chegados; nos túneis de circulação dos militares mas também nos serviços de enfermaria que não conseguiram contrariar a doença e a morte.

Foi na principal fortaleza, onde hoje se localiza a cidade e reside a população de Terezín, que o regime hitleriano delimitou, em 1941, o gueto judaico. Ponto de trânsito para outros campos prisionais ou de concentração, na ex-União Soviética e na Polónia, por este espaço terão passado cerca de 150 mil homens, mulheres e crianças, provenientes da Boémia e da Morávia, mas também da Alemanha, da Áustria, dos Países Baixos, da Dinamarca, da Hungria e da Eslováquia. Antes de 1940, a população de Terezín rondava os 7000 habitantes. Durante o conflito, a demografia ascendeu a valores entre os 30 e 40 mil residentes. Em dezembro de 1942 a cidade atingiu o seu valor máximo - mais de 58 mil pessoas, numa área de 10,5 ha. Espaço de desterritorialização, confinamento espacial e enclausuramento coletivo, também aqui a supressão dos direitos humanos, a violência e a morte se inscreveram na narrativa do lugar. Calcula-se que cerca de $25 \%$ dos deportados aqui terá perecido, facto que justificou a construção de um crematório. Entendendo a desterritorialização, seguindo Rogério Haesbaert (2004), enquanto 
limitação de movimentos, supressão de liberdade e confinamento das opções territoriais, o gueto de Theresienstadt expressa um sistema disciplinar extremo, uma muralha que envolveu um espaço sobrelotado com condições dramáticas de subsistência, alojamento e higiene.

Terezín foi também um espaço de simulação quando, em 1944, se preparou e encenou o gueto para uma visita do Comité Internacional da Cruz Vermelha. Para iludir o mundo e negar o sobrepovoamento, deportaram-se residentes para campos como Auschwitz; criaram-se espaços verdes; simularam-se instalações médicas e sanitárias; encenou-se uma vida urbana de qualidade com espaços públicos de encontro e convívio, cafés e escolas. Como complemento, produziu-se um filme de encenação daquele que seria um modelo do modo como o regime hitleriano deslocou mas, ao mesmo tempo, devolveu um espaço livre e de qualidade à comunidade judaica. Depois das filmagens desta paisagem falsa, a maior parte dos figurantes foi deportada para Auschwitz.

É a memória deste espaço e das narrativas que lhe dão densidade e espessura que agora se abre ao turismo e à visita de culto. Um museu judaico na antiga escola, os arruamentos do gueto, os lugares clandestinos de prática religiosa, os aposentos de judeus deportados e recém-chegados, o crematório, o cemitério judaico, o memorial ao Exército Vermelho libertador, são alguns dos elementos espaciais que narram atrocidades.

Este espaço de múltiplas narrativas é, desde a época comunista, um centro de atenção e visita embora nem sempre pelas mesmas razões. Após a importância pedagógica enquanto paisagem de glorificação do comunismo e da intervenção libertadora do Exército Vermelho, que ali levou gerações de jovens educados no regime de inspiração soviética, Terezín emerge como centro turístico de memória da II Guerra Mundial e do Holocausto. Como se refere numa publicação institucional (MONUMENT TEREZín, 2003, p. 64), "La vocation du Monument Terezín est avant tout de rappeler la mémoire des victimes de l'occupation nazie et la souffrance des prisonniers des appareils de répression de Terezín et Litoměřice. Il a pour mission de prendre soin de ces lieux de mémoire, liés à ce chapitre tragique de notre histoire moderne". Sendo possível a realização de visitas guiadas em diferentes idiomas, nessa apresentação não se escondem as atrocidades associadas aos lugares visitados. Pelo contrário, a violência que marcou este território de confinamento e desterritorialização 
é uma narrativa central no discurso de divulgação turística e pedagógica de Terezín ${ }^{45}$.

Numa rota que pode também incluir Praga, o número de visitantes, nacionais e estrangeiros, tem revelado valores consistentes em torno dos 200 mil anuais, diversificando-se entre jovens, adultos, judeus e não judeus, checos, polacos, alemães e israelitas, entre outros. Em 2010, a fortaleza pequena recebeu 212630 visitantes e o museu judaico, na fortaleza principal, 145057. Em termos de valores acumulados, entre 2002 e 2010, a antiga prisão da Gestapo recebeu 1981203 visitantes e o museu 1329987. No primeiro caso, 77.9\% dos visitantes foram estrangeiros. No segundo, esse valor ascendeu a 75\%, proporção que evidencia a importância deste lugar em redes alargadas de turistas e visitantes (Figura 8).
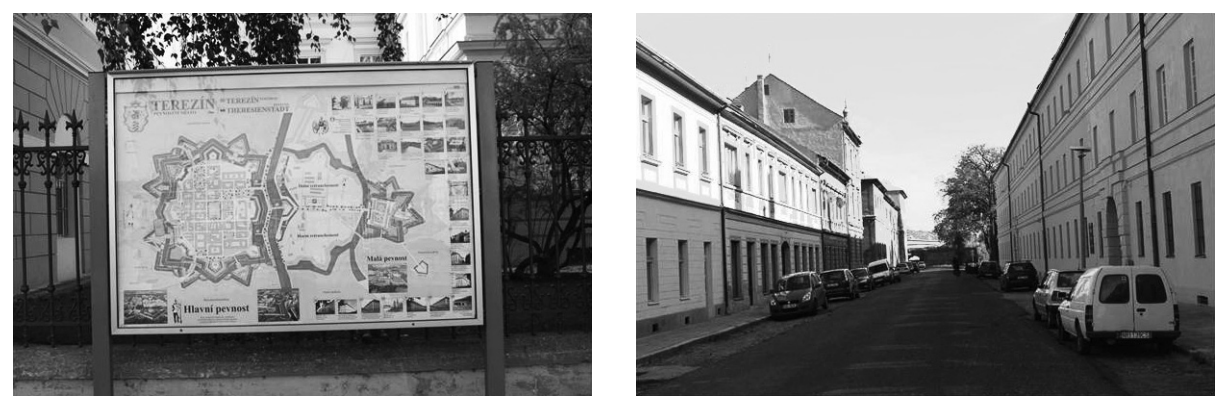

Figura 8 - Esquerda, cartaz de orientação turística, onde é visível a estrutura espacial do memorial, dividido entre a fortaleza pequena e a fortaleza principal.

Direita, imagem atual de uma rua do antigo gueto.

\footnotetext{
45 Esta atmosfera de horror é amplamente divulgada pelos materiais oficiais e não oficiais, diretos e indiretos, de promoção turística do lugar, como se pode verificar pelo texto que acompanha a divulgação de Terezín no site de viagens fodors.com (em http://www.fodors.com/): "Iust the word Terezin (Theresienstadt in German) immediately recalls the borrors of the Jewish Holocaust for Czechs. As the main Nazi concentration camp in Bohemia, Terezin held much of Pragues large prewar Jewish population during the war. It wasn,t a death camp in the way that Auschwitz was-though in the end, very few of the tens of thousands of Jews transported there survived the war. (...) Through 1944 and 1945, as the Nazis, war effort soured, the masquerade of their benevolence in Terezin was dropped. Train transports to Auschwitz and other death camps to the east were stepped up to a rate of several a week. (...) The shock in visiting Terezin today is that its pretty much remained the same. To their credit, Czechs have done very little to dress it up for visitors. Youre free to walk the town's rundown streets and imagine what it must have been like to be beld prisoner there. It,s dark, depressing, and at the same time, profoundly engrossing".
} 
Por outro lado, Terezín continua a ser ponto de convergência de estudantes, voluntários, artistas e outros que, seguindo o trabalho do Departamento de Educação, participam em múltiplas atividades que envolvem seminários, cursos, concertos ou exposições temporárias e/ou permanentes.

Este memorial organiza atividades de cooperação em rede com organizações de vítimas, outros museus e memoriais à escala internacional, como o Museu Estatal Auschwitz-Birkenau, o United States Holocaust Memorial Museum (em Washington), a Casa Anne Frank (em Amesterdão) ou o New York's Museum of Jewish Heritage. De facto, enquanto território de relação com o passado, a um grupo e a um acontecimento, este é um dos lugares de filiação identitária da comunidade judaica mundial. Terezín participa numa rede global de lugares e instituições que suportam uma identidade coletiva e de diáspora. À entrada da fortaleza pequena levantou-se uma Estrela de David, um traço de identificação étnica que predomina e se impõe, apesar de este ser um lugar de múltiplas vítimas não judaicas.

Quanto à cidade em si - a sua escassa centralidade, a atual baixa densidade demográfica de uma população maioritária não judaica de commuters que, apesar de ali residirem, trabalham no exterior, sobretudo em Litoměřice e Praga, dão a Terezín uma particular atmosfera de excesso de passado, um lugar tranquilo mas que regista acontecimentos pretéritos ainda presentes. Neste caso, a fortaleza, o Holocausto, o gueto, a prisão nacional-socialista e todos os acontecimentos associados à II Guerra Mundial absorveram o lugar, dando-lhe alguma relevância turística mas não the abrindo as portas do futuro. Numa visita a esta cidade, sente-se e respira-se o passado mas a dinâmica da contemporaneidade parece estar ausente. Numa primeira perceção, nota-se um espaço lento e de memórias, uma cidade que transporta o drama mas que se encolhe perante o presente. Ali se comemoram dias nacionais e internacionais de homenagem às vítimas da Alemanha hitleriana e se recordam os horrores do passado, mas também naquele lugar se celebra a libertação e o nacionalismo checo. O turismo, fluxo envolvido nesta trama complexa, mais que um fator de desenvolvimento local, é uma forma de ancorar este lugar a um passado que, tendo sido violento, persiste no tempo. Como refere um visitante num blogue de viagens, "I would not say this is a must see for everyone, only for those who are willing to see and hear the truth and accept buman failings" ${ }^{\prime 46}$.

${ }^{46}$ Citação retirada do site http://www.travelblog.org/Europe/Czech-Republic/), consultado a 21 


\section{Considerações Finais}

Prevenção e reconciliação, são estes os fundamentos do Turismo de Holocausto. Em sentido lato, o turismo não é apenas uma atividade económica ao encontro do lazer e do bem-estar mas um sistema que apropria lugares espessos com um passado, uma narrativa e uma atmosfera de atrocidades e sofrimento. Mais que a transformação insustentável de paisagens, como ocorreu com a massificação do lazer balnear em muitos lugares do mundo, o turismo faz parte de um complexo sistema de julgamento da História, aprisionamento do passado e defesa de um futuro que se deseja mais pacífico. Ainda sem um corpo teórico sedimentado, a apropriação turística do horror é apenas uma variável entre as múltiplas envolventes políticas e ideológicas que atravessam espaços mais pesados pela memória da violência. Terezín, pela patrimonialização in situ destes acontecimentos; pela ausência de equipamentos turísticos pós-modernos que acrescentem espetáculo às narrativas existentes e pelo trabalho pedagógico envolvido, aproxima-se da paisagem de memória e turismo hard citados por Stone (op. cit.). Esta cidade faz hoje parte de uma rede global de filiação da diáspora judaica. Também aqui, invocando o passado, a República Checa afirma a sua nacionalidade e independência. Na perspetiva local, o peso da História marca a cidade. Esta submete-se aos acontecimentos pretéritos e simplifica-se à imagem estereotipada da prisão e do gueto, ocorrências do passado que marcam o presente e que Terezín transportará para o futuro.

\section{Bibliografia}

Ashworth, G. J. 2002, "Holocaust Tourism: The Experience of Kraków-Kazimierz", International Research in Geographical and Environmental Education, vol.11, n 4, pp.363-367.

Ashworth, G. J. 2004, "Tourism and the Heritage of Atrocity: Managing the Heritage of South African Apartheid for Entertainment", T. V. Singh (Edit.),Tourism Seeks New Horizons: Strange experiences and stranger practices, CABI Publishing;. Wallingford.

Foley, M. \& Lennon, J. 2000, Dark Tourism. The Attraction of Death and Disaster, Cengage Learning Business Press, Stamford.

de junho de 2011. 
Haesbaert, R. 2004, O mito da desterritorialização, Bertrand Brasil; Rio de Janeiro.

Ivanov, S. 2009, "Opportunities for developing communist heritage tourism in Bulgaria”, Tourism Review, Vol. 57 No 2.

Light, D. 2000a, 'An Unwanted Past: contemporary tourism and the heritage of communism in Romania', International Journal of Heritage Studies, Vol. 6, No. 2.

Light, D. (2000b), 'Gazing on communism: heritage tourism and post-communist identities in Germany, Hungary and Romania', Tourism Geographies, 2(2).

Llipovetskyl, G.; Charles, S. (2011), Os tempos hipermodernos; Edições 70; Lisboa. Llipovetskyl,

Monument Terezín (2003), Terezín. Lieux de souffrance et d’héroisme; Terezín. Richards, Greg \& Wilson, Julie 2006, "Developing creativity in tourist experiences: A solution to the serial reproduction of culture?", Tourism Management, 27.

Ryan, C. (Ed.) 2007, Battlefield Tourism: History, Place and Interpretation, Elsevier Science, Amsterdam.

Spargo, R. C. \& Ehrenreich, R. M. (Ed.) 2010, After Representation? The Holocaust, Literature, and Culture, Rutgers University Press, New Brunswick.

Stangl, P. (2008), "The vernacular and the monumental: memory and landscape in post-war Berlin", GeoJournal, nº73.

Stone, P. R. (2006), "A dark tourism spectrum: Towards a typology of death and macabre related tourist sites, attractions and exhibitions", Tourism: An Interdisciplinary International Journal, vol. $54, n^{\circ} .2$.

Tarlow, P. E., 2005, "Dark Tourism. The appealing 'dark' side of tourism and more”, Marina Novelli (Ed.), Niche Tourism. Contemporary Issues, Trends and Cases; Elsevier, Amsterdam.

Terezín Memorial (2009), Terezín. Small Fortess. 1940-1945, Terezín.

Terezín Memorial (Vários anos), Annual Reports, Terezín.

Tumarkin, M. 2005, Traumascapes: The power and fate of places transformed by tragedy, Melbourne University Press, Melbourne. 